\title{
O USO DA METODOLOGIA TEAM BASED LEARNING COMO ESTRATÉGIA PARA REVISÃO DE CONTEÚDOS UTILIZANDO O SOFTWARE TBLActive
}

\section{ADRIANA PAULA ZAMIN SCHERER ${ }^{1}$.}

\author{
${ }^{1}$ Mestre em Computação pela Universidade Federal do Rio Grande do Sul (2002). Faculdade Dom Bosco \\ de Porto. adriana.scherer@gmail.com.
}

\section{RESUMO}

As metodologias ativas de aprendizagem tornam o aluno o centro do processo de aprendizagem. Dentre tais metodologias, a Team Based Learning destaca-se pelo aprendizado efetivo de conteúdos técnicos e pelo desenvolvimento da tomada de decisão, do trabalho em equipe e colaborativo. A metodologia é dividida em 03 (três) partes: preparo prévio que ocorre em ambiente externo à sala de aula; garantia de preparo, ocorre no ambiente de sala de aula e é composto por uma dinâmica de respostas a um conjunto de questões que os estudantes respondem individualmente e na sequência em equipes; aplicação de conceitos é o momento em que os estudantes aplicam o que aprenderam através da resolução de problemas que, normalmente, envolvem aspectos com a área de atuação futura do aluno. Este trabalho tem o objetivo de relatar a experiência de utilização dessa metodologia, em uma turma de estudantes do Curso de Sistemas de Informação de uma instituição de ensino privado. Ao final da atividade, os estudantes responderam a um questionário avaliativo e os resultados demonstraram um grau de satisfação muito elevado com a aplicação do método e uma percepção de aprendizado significativo.

Palavras-chave: Metodologias Ativas; Team Based Learning; Aprendizagem Cooperativa; Sistemas de Informação; Revisão de Conteúdo.

\section{THE USE OF THE TEAM BASED LEARNING METHODOLOGY AS A STRATEGY FOR CONTENT REVIEW USING THE TBLActive SOFTWARE}

\begin{abstract}
Active methodologies of learning make the student the center of the learning process. Among these methodologies, the Team Based Learning stands out for effective learning of technical content and development of decision-making process as well as teamwork and collaboration. The methodology is divided into 03 (three) parts: prior preparation that happens outside the classroom; Preparation guarantee occurs in the classroom environment and is composed by a dynamic response of questions which initially is answered individually and later in teams by the students; Application of concepts is the moment when students apply what they have learned by solving problems that normally
\end{abstract}


involve aspects of the student's future area of expertise. This paper purposes to report the experience of this methodology usage of an Information Systems group of students into a private educational institution. At the end of the activity, the students filled out an evaluative questionnaire and the results showed high satisfaction with the application of this method and significant learning perception.

Keywords: Active Methodologies; Team Based Learning; Cooperative Learning; Information systems; Content Review.

\section{INTRODUÇÃO}

Um cenário bastante comum encontrado nas salas de aula de todos os níveis de ensino são estudantes com postura passiva e que se mantém à margem das discussões sobre os conteúdos. São tipicamente salas de aula conduzidas por métodos tradicionais, com aulas expositivas e centradas na figura do professor. Normalmente, as atividades dos alunos se resumem a trabalhos individuais e a resolução de extensas listas de exercícios que também serão norteadoras das questões aplicadas nos testes avaliativos. E, mesmo assim, verificam-se altos índices de reprovação.

Sabe-se que a metodologia utilizada em sala de aula não é o único fator que influencia os índices de reprovação. Contudo, estudos apontados por Oliveira; Araújo; Veit (2016) demonstram que o uso de metodologias ativas tem diminuído os índices de reprovação.

Ainda que obtenham êxito na vida acadêmica, os estudantes que são mantidos no cenário do ensino tradicional e que são receptores passivos do conhecimento, não finalizam seus cursos preparados para atuar no mercado de trabalho do mundo globalizado. A eles, falta a habilidade de vincular a teoria e a prática e o desenvolvimento de competências para o trabalho em equipe, tais como a resolução de conflitos e o aprimoramento do poder de argumentação.

Novamente, as metodologias ativas de aprendizagem têm se mostrado como alternativa para o desenvolvimento das habilidades adicionais ao conhecimento técnico e que são tão importantes quanto ele para o futuro dos profissionais no mercado de trabalho.

Dentre tantas formas de ensinar através do uso das metodologias ativas, a Team Based Learning (TBL) ou Aprendizagem Baseada em Equipes destaca-se por possibilitar um ambiente motivador e promotor da cooperação. Além do alto 
envolvimento dos alunos, a TBL promove uma otimização do processo de ensinoaprendizagem e uma maior qualidade na comunicação, proporcionada pelo trabalho nas equipes (CLEMENTE et al., 2019).

O presente trabalho tem como objetivo relatar as experiências de uma atividade de revisão de conteúdos utilizando a metodologia Team Based Learning com o software TBLActive em um Curso de Sistemas de Informação de uma instituição privada de ensino superior.

Isto posto, além desta introdução, o artigo apresenta-se dividido em seis seções. Na seção 2, será apresentado o referencial teórico acerca da metodologia Team Based Learning. Na seção 3, será descrita a forma como a atividade foi conduzida e apresentandos os procedimentos metodológicos utilizados para o levantamento dos dados. A seção 4 apresentará os resultados obtidos e a discussão sobre eles. E, por fim, as considerações finais com a síntese do trabalho.

\section{REFERENCIAL TEÓRICO}

A metodologia Team Based Learnig foi desenvolvida na Universidade de Oklahoma para os cursos de Administração, em 1970, por Larry K. Michaelsen. Essa metodologia busca obter os benefícios de pequenos grupos de trabalho que estimulam o processo de argumentação e de contato com diferentes percepções que podem conduzir a um melhor entendimento dos conteúdos abordados.

De acordo com Camargo e Daros (2019) e Clemente et al. (2019), a TBL baseiase no construtivismo, em que se pressupõe que o aluno poderá construir a sua própria aprendizagem ao interagir com professores e colegas. A metodologia envolve o gerenciamento das equipes promovendo o comprometimento individual em prol do grupo, desenvolvendo a confiança entre os membros da equipe.

Souza e Penha (2018) afirmam que a metodologia é dividida em 03 (três) etapas:

a. Preparo prévio: pode incluir filmes, estudos individuais, leitura de artigos, dentre outros. Esta etapa ocorre em ambiente externo e deve ocorrer anteriormente ao trabalho que será realizado na sala de aula. Esta etapa é fundamental para o sucesso da prática com a metodologia, uma vez que o sucesso do trabalho na sala de aula, tanto a 
etapa individual, quanto a etapa nas equipes, requer o conhecimento prévio adquirido pelos alunos.

b. Garantia de Preparo: esta etapa ocorre em sala de aula e consiste em responder, sem consulta, questões de múltipla escolha primeiro individualmente - iRAT (Individual Readiness Assurance Test) e depois em equipe - gRAT (Group Readiness Assurance Test). Cada questão de múltipla escolha pode ter 04 (quatro) ou 05 (cinco) alternativas, sendo apenas uma delas a correta, e vale 04 (quatro) ou 05 (cinco) pontos, respectivamente. No iRAT, o aluno ao responder cada questão distribui os pontos dela entre as alternativas. Considerando uma questão com 04 (quatro) alternativas, caso ele tenha certeza da resposta, coloca os 04 (quatro) pontos na alternativa que ele considera a correta; caso ele fique em dúvida entre 02 (duas) alternativas ele pode distribuir 02 (dois) pontos em cada alternativa que gerou a dúvida; e assim por diante. Isto é, o aluno distribui os pontos na questão conforme a certeza ou incerteza da resposta correta. Uma vez distribuídos os pontos, o aluno salva a resposta e vai para a próxima questão, e assim sucessivamente até finalizar o conjunto de questões. No gRAT, a equipe irá responder ao mesmo conjunto de questões. No entanto, o mecanismo de pontuação é diferente, não há mais possibilidade de distribuir os pontos, ou seja, a questão vale a sua pontuação total e, em cada erro, ela vai perdendo um ponto, até que se sobrar apenas a resposta correta, ela não valerá nenhum ponto. A seguir, abre-se o momento para a Apelação que é quando as equipes podem recorrer ao não concordar com a resposta indicada como correta. Bollela at el. (2014) afirmam que a Apelação deve conter a argumentação e a indicação das fontes bibliográficas relacionadas que justifiquem o erro e/ou a resposta correta. São requisitos para a Apelação: deve ser feita por escrito, toda a equipe deve participar da elaboração, em formulário próprio definido pelo professor e encaminhada ao professor. As equipes cujas apelações estiverem de acordo com conteúdo e argumentação ganham os pontos relacionados a questão. Esse artifício torna-se mais um componente de oportunidades para ampliar o conhecimento e as habilidades de trabalho em equipe.

c. Aplicação de conceitos: é o momento em que os estudantes aplicam o que aprenderam através da resolução de problemas que, normalmente, envolvem aspectos com a área de atuação futura do aluno. Esta etapa ocorre em sala de aula e requer um tempo maior de execução do que a etapa anterior. Podem ser utilizados diversos 
problemas, sendo que, para cada um, os alunos discutem, escolhem e revelam suas escolhas e, após, ocorre a discussão dos conteúdos e respostas, com a mediação do professor. Este é o momento em que o professor poderá retomar o conteúdo, caso se faça necessário.

Para a elaboração e resolução de problemas, deve-se levar em conta o princípio dos 4S, de acordo com Krug et al. (2016):

a) SIGNIFICANT (Problema significativo): Os problemas que serão apresentados aos alunos deverão ser significativos, relevantes e originais.

b) SAME (Mesmo problema): Todas as equipes trabalham com o mesmo problema. Isto facilita futuros debates.

c) SPECIFIC (Escolha específica): As equipes selecionam a melhor escolha de uma lista limitada de opções. Assim, nunca se deve solicitar que as equipes produzam documentos longos.

d) SIMULTANEOUS REPORT (Relatos simultâneos): As equipes relatam suas respostas de maneira simultânea e não de maneira sequencial. Ao perceber que equipes diferentes possam ter escolhas diferentes, favorece-se o início de um debate produtivo entre as equipes.

Na metodologia TBL, originalmente proposta por Michaelsen, os testes são realizados em papel ou em um modelo de "raspadinha". No entanto, a utilização de ferramentas digitais pode auxiliar na implementação de atividades com a metodologia TBL, pois acrescentam à experiência aspectos lúdicos e de agilidade na condução da etapa de Garantia de Preparo. Souza e Penha (2019) relatam, entre outros softwares, a possibilidade de uso do Socrative que pode ser utilizado para a coleta dos resultados individuais dos estudantes. Marques et al. (2018, p. 1), em seu trabalho, relata que o uso do software "[...] possibilita o feedback imediato e relatórios estatísticos para auxiliar os docentes no diagnóstico, na avaliação e na identificação dos conteúdos que necessitam de maiores esclarecimentos".

\section{MÉTODOS E TÉCNICAS}

A metodologia Team Based Learning foi aplicada na disciplina de Banco de Dados B do curso de Sistemas de Informação, em uma instituição de ensino superior 
privado. Os alunos matriculados nesta disciplina são aqueles que já cursaram $80 \%$ das disciplinas obrigatórias, configurando um público com nível cognitivo avançado e nenhum deles havia tido experiência anterior com a metodologia.

A experiência relatada neste trabalho foi utilizada como recurso didático para revisão de conteúdo em uma aula que antecedeu a prova final da disciplina e teve como metas de aprendizagem revisar os conteúdos trabalhados durante o semestre e identificar possíveis falhas de conhecimento acerca dos conteúdos. Além dos aspectos cognitivos, essa experiência buscou aprimorar as competências relacionadas ao trabalho em equipe, tais como: mediação de conflitos, colaboração com a atividade proposta dentro dos grupos e capacidade de argumentação.

A condução da metodologia seguiu as etapas definidas pelo referencial teórico, conforme apresentado na seção 2.

Para o preparo prévio, com uma semana de antecedência, os alunos foram avisados de que, na próxima aula, seria realizada a atividade de revisão e, para isso, deveriam revisar os conteúdos trabalhados ao longo do semestre. Para esta disciplina, os materiais utilizados durante todas as aulas estavam disponíveis em área específica do Moodle e poderiam ser acessados pelos alunos a qualquer momento ao longo da semana.

No início da aula em que a metodologia foi aplicada, foi feita uma apresentação da metodologia Team Based Learning para que os alunos pudessem trabalhar adequadamente para atingir os objetivos estabelecidos pelo professor. Além disso, foi feita uma breve demonstração do software TBLActive que foi utilizado para a etapa de Garantia de Preparo. Nesse momento, os alunos puderam fazer experimento do software e sua relação com a metodologia exposta anteriormente através de um exercício padrão sem relação com o conteúdo da disciplina. O software pode ser acessado gratuitamente no link www.tblactive.com.br.

Para a etapa da Garantia de Preparo, em que foi utilizado o software TBLActive, foram elaboradas 10 (dez) questões que envolveram os conteúdos trabalhados ao longo do semestre. Em nenhuma questão, utilizou-se o recurso de Apelação, previsto na metodologia, descrito na seção 2. Conforme estabelece a metodologia citada na seção 2 , os alunos responderam às questões individualmente e, após, organizaram-se em equipes 
para a resolução do mesmo conjunto de questões. A organização das equipes se deu por afinidade, resultando em 02 (duas) equipes com 05 (cinco) integrantes cada.

Ao término desta etapa, as questões foram repassadas uma a uma retomando os conceitos que foram abordados, os erros e os acertos individuais e das equipes. A discussão acerca do desempenho individual e em equipe foi fundamentado sobre os relatórios gerados pela ferramenta TBLActive.

Já para a etapa de Aplicação de Conceitos, foram utilizados dois problemas que foram resolvidos sequencialmente e seguindo as etapas previstas pelo referencial teórico da metodologia, conforme abordado na seção 2. Em nenhum dos dois problemas utilizou-se o recurso de Apelação. Após a aplicação de cada problema, houve a discussão das respostas e, novamente, a retomada do conteúdo exigido pelas questões, com esclarecimentos de dúvidas e questionamentos realizados pelos alunos em suas equipes.

Ao término da atividade foi entregue aos alunos um questionário de avaliação semiestruturado, elaborado pelo Núcleo de Apoio e Inovação Pedagógica (NAeIP), para ser respondido pelos alunos sobre a metodologia aplicada. O questionário estava dividido em 4 (quatro) partes, a primeira buscava verificar o grau de aprendizagem com a metodologia utilizada, sob o ponto de vista do aluno, e era composta por 01 (uma) pergunta fechada. A segunda parte procurava identificar $o$ grau de satisfação/insatisfação com a metodologia, e era composta por 01 (uma) pergunta fechada e 02 (duas) perguntas abertas. A terceira parte investigava as percepções dos alunos acerca da comparação com uma aula tradicional expositiva e era composta por 02 (duas) questões fechadas. A quarta parte buscava identificar as facilidades e as dificuldades encontradas pelos alunos durante o desenvolvimento da atividade utilizando a metodologia e era composta por 02 (duas) questões abertas.

\section{RESULTADOS}

A análise dos dados foi feita por meio de estatística descritiva, gerando gráficos e quadros que demonstram os respectivos índices. Responderam ao questionário 10 (dez) alunos. 
Para verificar o grau de aprendizagem com a metodologia utilizado, foi perguntado aos alunos qual a sua percepção sobre o conhecimento adquirido através da aula com o uso da metodologia TBL, os resultados foram coletados e encontram-se no Gráfico 1.

Gráfico 1 - Grau de aprendizado do aluno.

\section{Creio que nesta aula:}

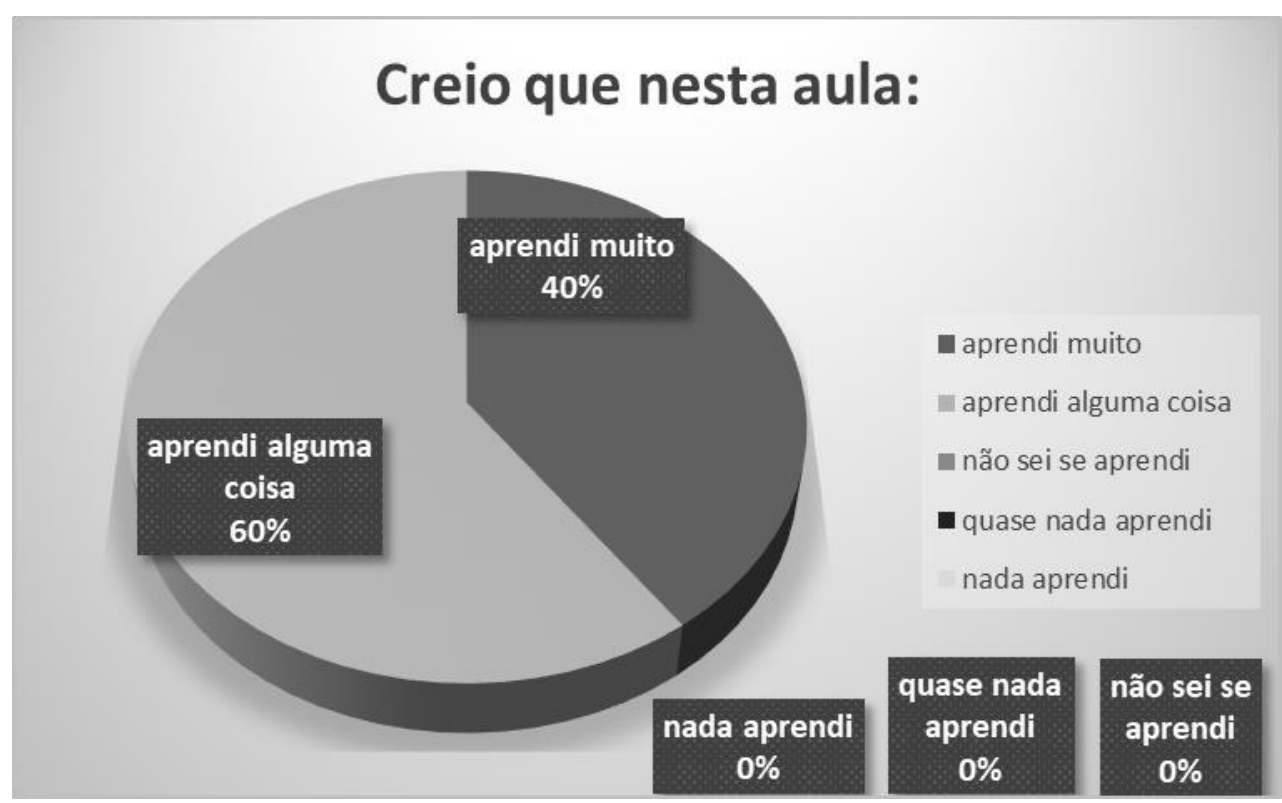

Fonte: Autoria própria (2019).

Ao analisar as respostas coletadas, percebe-se que $100 \%$ da amostra considerou ter aprendido os conteúdos trabalhos, em graus diferentes, mas ainda assim aprenderam com o uso da metodologia.

Para identificar o grau de satisfação/insatisfação, foi perguntado qual o nível de satisfação com o uso da metodologia e as respostas foram coletadas e organizadas conforme Gráfico 2. 
Gráfico 2 - Grau de satisfação do aluno

\section{Pessoalmente, me senti nesta aula:}

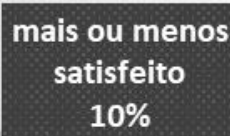

muito satisfeito

bastante satisfeito

mais ou menos satisfeito

bastante

satisfeito

- pouco satisfeito

indiferente

\section{$60 \%$}

indiferente

$0 \%$

pouco satisfeito

$0 \%$

Fonte: Autoria própria (2019).

Ainda na busca para a identificação do grau de satisfação/insatisfação dos alunos, foi perguntado o motivo da satisfação. Dos 10 (dez) alunos da turma, 07 (sete) registraram suas respostas e elas foram organizadas conforme o Quadro 1.

Quadro 1 - Motivos de Satisfação

\begin{tabular}{l|l}
\hline Relato 1 & É uma maneira de pensar melhor na decisão \\
\hline Relato 2 & Achei muito interessante o método de avaliação individual e em grupo \\
\hline Relato 3 & Estimula-se a troca de ideias em equipes \\
\hline Relato 4 & Teve discussão nos grupos para expor uma resposta \\
\hline Relato 5 & Dinâmico e divertido \\
\hline Relato 6 & O aprendizado foi melhor que aprender sozinho \\
\hline Relato 7 & A atividade se torna mais prática do que conceitual \\
\hline
\end{tabular}

Fonte: Autoria própria (2019).

Igualmente, foi perguntado o motivo da insatisfação e somente 03 (três) alunos registraram duas respostas e elas encontram-se no Quadro 2.

Quadro 2 - Motivos de Insatisfação

\begin{tabular}{l|l}
\hline Relato 1 & Não houve frustração \\
\hline
\end{tabular}




\begin{tabular}{l|l}
\hline Relato 2 & Não fiquei frustrado \\
\hline Relato 3 & Nenhuma \\
\hline
\end{tabular}

Fonte: Autoria própria (2019).

Um ponto importante desta etapa da avaliação foi identificar que a atividade satisfez 90\% dos discentes, sendo que 60\% afirmaram terem ficado "bastante satisfeitos" e 30\% afirmaram que ficaram "muito satisfeitos", e apenas $10 \%$ afirmaram que ficaram "mais ou menos satisfeito". Esses índices de satisfação, juntamente com a análise das respostas qualitativas apresentadas no Quadro 1, confirmam que o trabalho em equipe sustentado pela metodologia TBL agrega significativa apreciação ao uso da metodologia, pois as discussões em grupos favorecem o aprendizado, confirmando as colocações de Camargo e Daros (2019) e Clemente et al. (2019). Outro reforço positivo analisado que demonstra a experiência exitosa sob o ponto de vista da satisfação dos alunos, é que nenhum deles apontou insatisfação, conforme o Quadro 2 explicita, confirmando, novamente, que os alunos ficaram satisfeitos com a experiência.

Para identificar as percepções dos alunos ao comparar a atividade desenvolvida com uma aula tradicional expositiva, perguntou-se se a atividade desenvolvida foi "Muito melhor", "Melhor", "Igual", "Pior", ou "Muito pior" e os alunos responderam conforme mostra o Gráfico 3.

Gráfico 3 - Comparação entre a metodologia ativa usada e a aula tradicional.

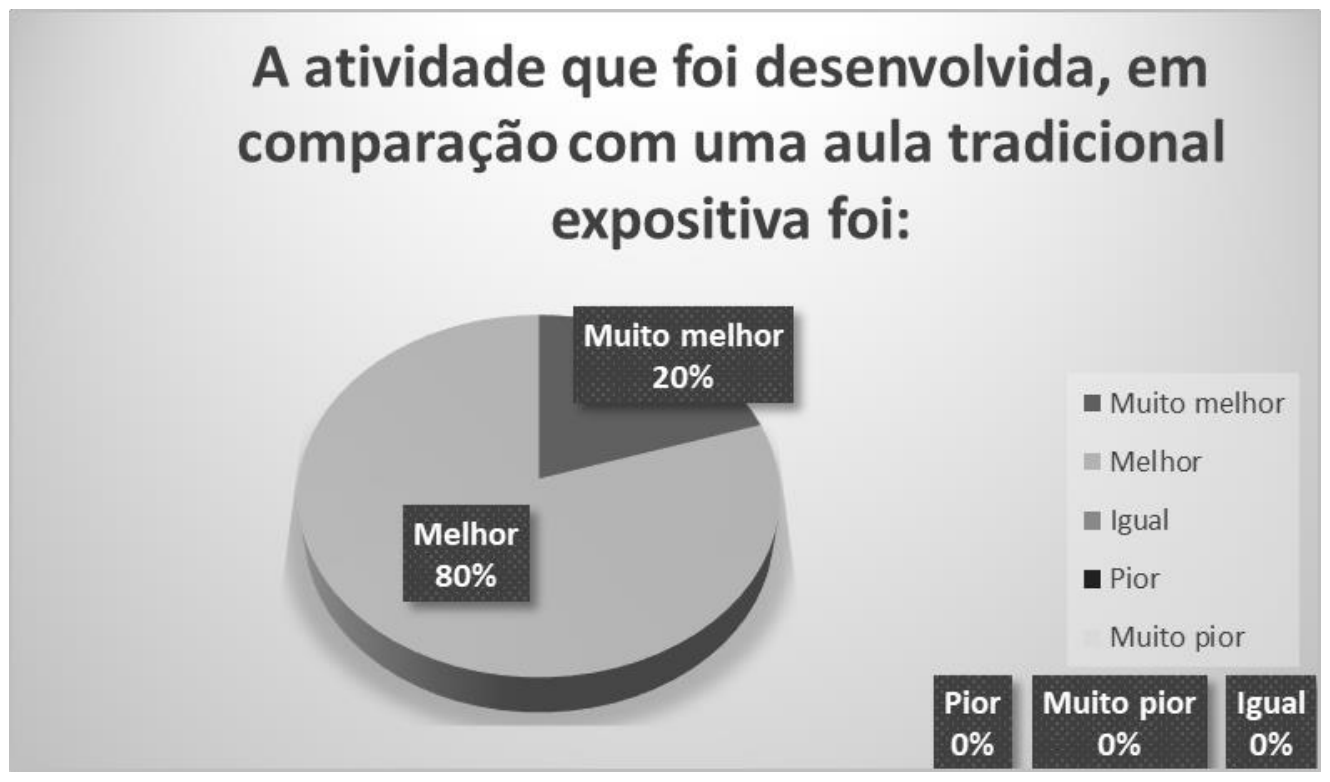

Fonte: Autoria própria (2019). 
Ainda para identificar as percepções de comparação da metodologia ativa TBL com uma aula tradicional expositiva, perguntou-se como foi o aprendizado. As respostas foram coletadas e encontram-se no Gráfico 4.

Gráfico 4 - Aprendizado gerado pela metodologia.

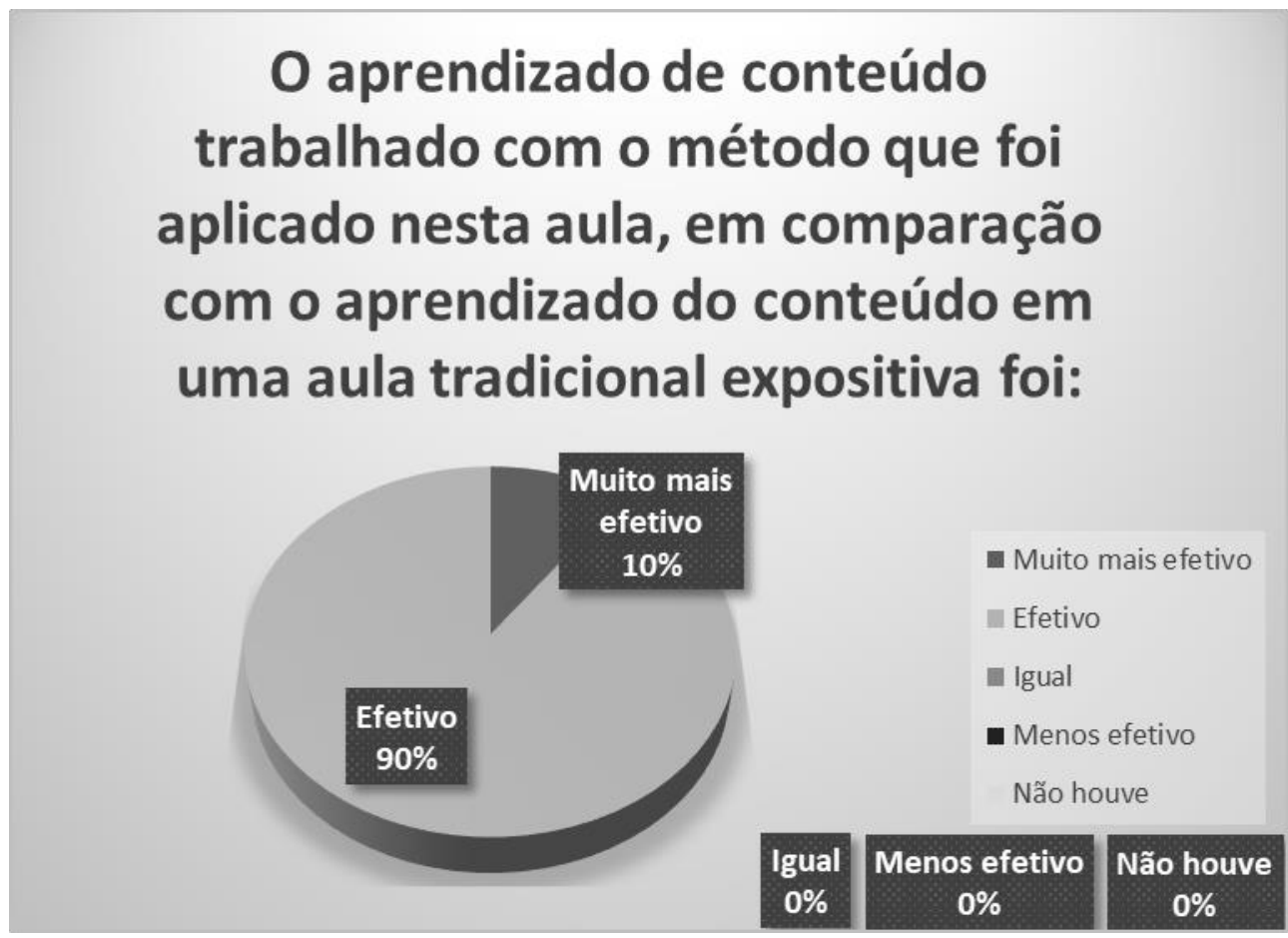

Fonte: Autoria própria (2019).

A análise das respostas que buscava verificar as percepções dos alunos ao comparar a atividade desenvolvida com uma aula tradicional expositiva, Figuras 3 e 4, mostrou que o nível de aprendizado do conteúdo foi considerado $100 \%$ melhor aprendido através do uso da metodologia do que na aula tradicional e $100 \%$ efetivo com o uso da metodologia do que com a aula tradicional.

Já para identificar as facilidades e dificuldades encontradas pelos alunos durante o desenvolvimento da atividade, iniciou-se por questionar quais facilidades foram encontradas e 08 (oito) alunos responderam esta questão. E as respostas estão apresentadas no Quadro 3. 
Quadro 3 - Facilidades encontradas

\begin{tabular}{l|l}
\hline Relato 1 & Discutir a tarefa \\
\hline Relato 2 & Ter o resultado individual e em grupo \\
\hline Relato 4 & Em desenvolver o pensamento durante as questões \\
\hline Relato 5 & Correção instantânea \\
\hline Relato 6 & Discussão em grupo para achar a resposta certa \\
\hline Relato 8 & Atividade em grupo \\
\hline Relato 9 & Clareza no aprendizado \\
\hline Relato 10 & Troca de informações entre a turma \\
\hline
\end{tabular}

Fonte: Autoria própria (2019).

Ao analisar as respostas dos alunos, percebe-se que as facilidades apontadas estão vinculadas ao principal propósito da metodologia TBL que é a aprendizagem ocorrendo dentro das equipes de trabalho, uma vez que relatam "Discutir a tarefa", "Ter o resultado ... em grupo", "Discussão em grupo para achar a resposta certa", entre outras. Tais respostas confirmam as colocações feitas por Camargo e Daros (2019) e Clemente et al. (2019) no que diz respeito aos benefícios do trabalho em equipe para o aprendizado dos alunos.

Ainda buscando identificar as facilidades e as dificuldades encontradas pelos alunos durante o desenvolvimento da atividade, posteriormente, questionou-se quais as dificuldades foram encontradas, sendo que 07 (sete) alunos responderam. E suas respostas estão apresentadas no Quadro 4.

Quadro 4 - Dificuldades encontradas

\begin{tabular}{l|l}
\hline Relato 1 & Nenhuma \\
\hline Relato 2 & Nenhuma \\
\hline Relato 3 & Algumas dificuldades de interpretação nas perguntas mais longas \\
\hline Relato 4 & Algumas perguntas estavam mal formuladas \\
\hline Relato 5 & Nenhuma \\
\hline Relato 6 & Nenhuma \\
\hline Relato 7 & Nenhuma \\
\hline
\end{tabular}

Fonte: Autoria própria (2019). 
A análise dos relatos chama a atenção pela tranquilidade com que os alunos passaram pela experiência com a metodologia utilizada, uma vez que não encontraram dificuldades. Cabe aqui destacar o relato 04 (quatro) que reporta dificuldades associadas às questões mal elaboradas, indicando que o conjunto de questões utilizado requer uma revisão mais atenta por parte do professor ao repetir a experiência para outra turma. $\mathrm{O}$ apontamento deste relato pode ter correspondência com o relato 03 (três) que depõe sobre dificuldades na interpretação das questões mais longas, podendo ser um reflexo de questões mal elaboradas.

A análise geral das questões qualitativas, apresentadas pelos Quadros 1, 2, 3 e 4, chama a atenção pela passagem transparente do uso do software TBLActive na etapa da Garantia de Preparo, pois, em nenhum momento, o uso do software foi mencionado. Isto pode ser um reflexo do fato de que a turma é parte do Curso de Sistemas de Informação e que está habituada ao uso de softwares para trabalhos realizados em sala de aula. No entanto, pode ser consequência do fato de que nenhum dos alunos havia tido experiência anterior com a metodologia TBL, assim assumindo para si próprios que o software é inerente ao processo da metodologia, tornando o seu uso dispensável de observações.

\section{CONSIDERAÇÕES FINAIS}

É um fato que, no mercado de trabalho globalizado para o qual os estudantes do ensino superior estão sendo preparados, não há mais espaço para profissionais com o saber compartimentado e que não conseguem trabalhar em equipe. O século XXI precisa de profissionais autodeterminados, autoconfiantes, com conhecimento duradouro, mas, sobretudo, que saibam compartilhar seus conhecimentos e aprender com suas equipes de trabalho.

As metodologias ativas têm se destacado como aliadas ao processo de ensinoaprendizagem ao sugerir novas práticas de sala de aula com diferentes abordagens, mas que convergem para o aprimoramento das competências cognitivas, pessoais e sociais. A Team Based Learning é uma dentre tantas metodologias que propõem que os estudantes saiam das suas zonas de conforto e interajam com os demais colegas de aula. 
Ela é composta pelas etapas de preparo prévio, garantia de preparo e aplicação de conceitos (SOUZA e PENHA, 2018).

A experiência reportada neste trabalho apontou para uma participação ativa dos alunos, com altos graus de satisfação, sem mencionar frustrações e as dificuldades apontadas remetem à formulação das perguntas utilizadas no conjunto de questões, sem abordar, em nenhum momento, apontamentos relativos à metodologia utilizada. As experiências vivenciadas pelos estudantes durante a atividade e coletadas na avaliação remetem à significância do trabalho que é desenvolvido nas equipes, na sua contribuição como fator facilitador para o desenvolvimento dos aspectos cognitivos e o processo de aprendizagem.

\section{REFERÊNCIAS}

BOLlELA, V. R.; SENGER, M. H.; TOURINHO, F. S. V.; AMARAL, E. S.. Aprendizagem Baseada em Equipes: da teoria à prática. Revista da Faculdade de Medicina de Ribeirão Preto e do Hospital das Clínicas da FMRP Universidade de São Paulo. SIMPÓSIO: Tópicos fundamentais para a formação e o desenvolvimento docente para professores dos cursos da área da saúde vol. $47, \mathrm{n}^{\circ} 3$ - julho/setembro de 2014. Disponível em http://revista.fmrp.usp.br/2014/vol47n3/7_Aprendizagem-baseadaem-equipes-da-teoria-a-pratica.pdf. Acesso em 15 de outubro de 2019.

CAMARGO, F.; DAROS, T.. A sala de aula inovadora: estratégias pedagógicas para fomentar o aprendizado ativo. Porto Alegre: Penso, 2018.

CLEMENTE, D. M.; CARVALHO, J. J.; LIMA, L. M. E. S.; SCHUAB, M. R.; CHAVES, P. J.. Aplicação do TBL sob a perpectiva de diferentes áreas do conhecimento In: NEVES, V. J.; LIMA, M. T.; MERCANTI, L. B.; COSTA, D. J. A. (org.). Metodologias Ativas: inovações educacionais no ensino superior. Campinas: Pontes Editores, 2019. p. 213-223.

KRUG, R. R.; VIEIRA, M. S. M.; MACIEL, M. V. A.; ERDMANN, T. R.; VIEIRA, F. C. F.; KOCH, M. C.; GROSSEMAN, S. O "Bê-Á-Bá" da Aprendizagem Baseada em Equipe. Revista Brasileira de Educação Médica. Vol.40 no.4 Rio de Janeiro out./dez. 2016

MARQUES, A. P. A. Z.; MESSAGE, C. P.; VILHEGAS, V. P. P.; GITAHY, R. R. C.. Relato de experiência: aplicação da metodologia Team Based Learning com uso do software TBL Active. In: ETIC - Encontro de Iniciação Científica. Anais do Encontro Toledo de Iniciação Científica Prof. Dr. Sebastião Jorge Chammé - Centro Universitário Antônio Eufrásio de Toledo de Presidente Prudente. v. 14, n. 14, 2018. 
OLIVEIRA, T. E.; ARAÚJO, I. S.; VEIT, E. A. Aprendizagem Baseada em Equipes (Team-Based Learning): um método ativo para o Ensino de Física. Caderno Brasileiro de Ensino de Física, v. 33, n. 3, p.962-986, dez, 2016.

SOUZA, R. G. ; PENHA, R. C.. Aprendizagem Baseada em Equipes na formação médica In: NEVES, V. J.; LIMA, M. T.; MERCANTI, L. B.; COSTA, D. J. A. (org.). Metodologias Ativas: inovações educacionais no ensino superior. Campinas: Pontes Editores, 2019. p. 133-144. 